\title{
Diagnostics of geomagnetically-induced currents in high-tension electric transmission lines
}

\author{
Vladimir Sivokon ${ }^{1,2^{*}}$, Nina Cherneva $^{1}$ and Evgeniy Malkin ${ }^{1}$ \\ ${ }^{1}$ Institute of Cosmophysical Research and Radio Wave Propagation FEB RAS, Russia \\ ${ }^{2}$ Kamchatka State Technical University, Russia
}

\begin{abstract}
The problem of geomagnetically-induced currents (GIC) effect on electrotechnical systems is topical as long as uninterrupted power distribution is critically important for all the spheres of human activity. Our investigations showed the possibility of GIC diagnostics based on the estimates of industrial current higher harmonics and showed that even harmonics correlate with the Earth magnetic field changes in a greater degree. However, the measurements carried out in $220 \mathrm{~V}$ network showed low and not always univocal correlation of the processes. Thus, we propose a technique for diagnostics of geomagnetically-induced currents in high-tension electric transmission lines ${ }^{* *}$.
\end{abstract}

\section{Introduction}

In order to estimate the degree of GIC manifestation in electrotechnical systems, direct measurements in a ground circuit or calculation on the basis of magnetic data is applied. The first case assumes installation of additional equipment into the electric transmission system that is always associated with difficulties to obtain permission from operating organizations. The second way assumes construction of an electrotechnical system model which takes into account many factors such as system conductor configuration and topology, electrodynamic characteristics of geological substrate etc. It is known that in electric networks transformers suffer the most from GIC effect. Their breakages are determined by the increase of current harmonic components in the conditions of GIC flow though electrical winding. In our method, current higher harmonic variations are used to realize GIC diagnostics [1]. In order to improve the efficiency of this technique we suggest applying indirect measurements in high-tension electric transmission lines.

\footnotetext{
*Corresponding author: sivokon.vladimir@yandex.ru

** The work was supported by RFBR Grant No.19-05-00543
} 


\section{Method justification}

The results of our observations [2,3], which have been carried out for several years at three sites of Kamchatka, showed correlation of harmonic level variations with magnetic field changes up to 0.5 in a number of cases. We have stated that even harmonics have the best correlation. However, network abundance with nonlinear consumers, which contribute the most into the industrial current unsinusoidality, limit the possibility of further increase of this method efficiency. Consequently, it is necessary to minimize the effect from nonlinear consumers on measurement process that is possible during theme measurements in high-tension electric transmission lines. In this case we should solve two problems, they are:

1. As our observations showed, it is inexpediently to apply a sum of higher harmonic components as GIC marker. Consequently, it is necessary to determine the harmonic the most sensitive to GIC manifestation.

2. It is necessary to develop a technique to retrieve the required information from the high-tension line without any coordination with an operating organization.

When determining harmonic optimal number, the following approach was applied. In radio engineering, to determine the harmonic amplitude, Berg coefficients are used. For the harmonics higher than the second one are determined as

$$
\alpha(\theta)=\frac{2(\sin \theta \cos \theta-n \cos n \theta \sin \theta)}{\pi n\left(n^{2}-1\right)(1-\cos \theta)}
$$

where $\theta$ is a cutoff angle, $n$ is a harmonic number.

As long as the deviation of intensity form in the network is not large, the cutoff angle is also small. On the basis of these conditions, we calculated and constructed Berg coefficient dependence for even harmonics (Fig. 1).

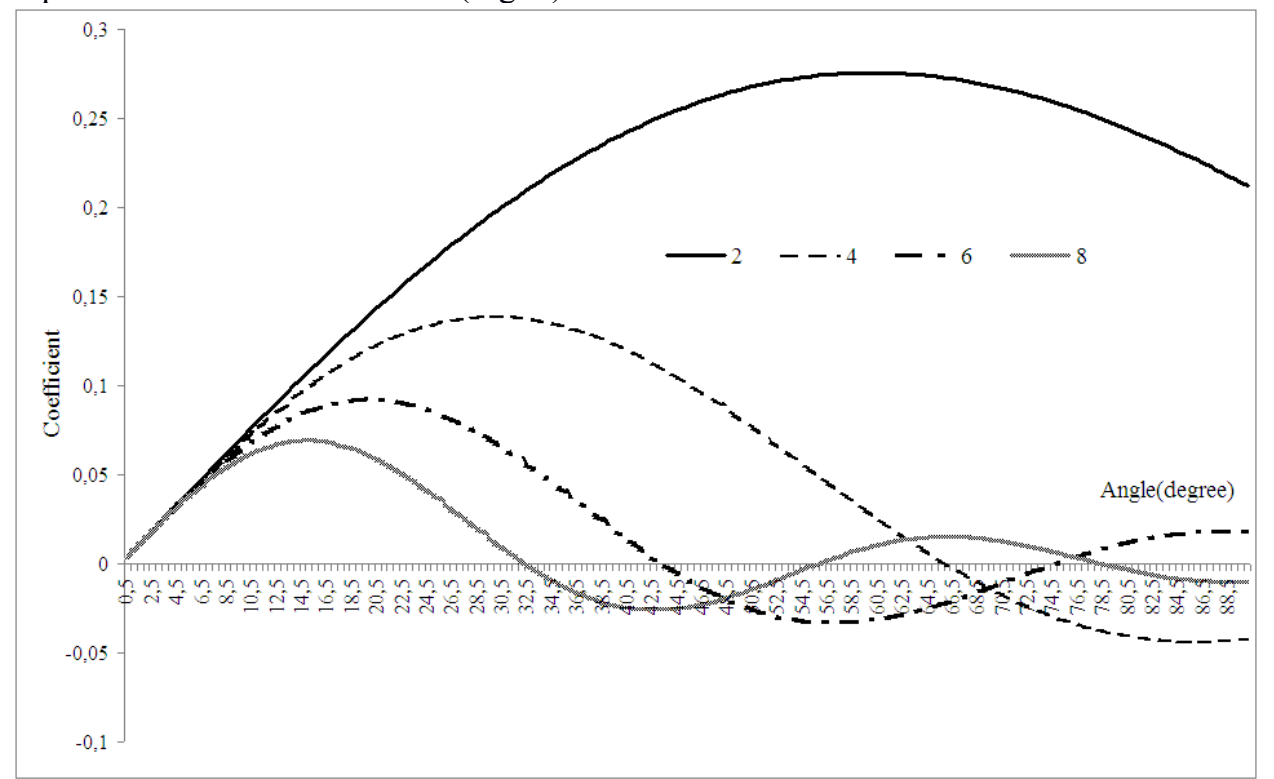

Figure 1. Berg coefficient dependence on cutoff angle

The figure shows the dependences for harmonics 2, 4, 6 and 8. It follows from the graph that for small cutoff angles, harmonics with large numbers have the maxima of Berg 
coefficient. In this case, the harmonic value decreases. Thus, we apply harmonics 6 and 8 for the diagnostics.

On the grounds of the analysis of electric network equipment topology and content in Kamchatka, we came to the conclusion that the most suitable for the observations is the Mutnovskaya Hydro-Electric Power Station line, «Avacha» substation. «Karymshina» observatory of IKIR FEB RAS is located at a distance of about two kilometers from the line. Equipment is powered from accumulator and solar batteries that allows us to minimize nonlinear consumer harmonics. $220 \mathrm{kV}$ voltage is used for electric energy transition in the line. Having calculated the field intensity generated by the line, we obtained that field intensity of about $4 \mathrm{mV} / \mathrm{m}$ is generated by the line at the indicated distance. Consequently, to record harmonics steadily, a device having the sensitivity of not less than $4 \mathrm{mV} / \mathrm{m}$ is required. As such, we used the VLF detector of the Laboratory of Electromagnetic Radiation IKIR FEB RAS.

\section{Observation results}

The data obtained from the VLF detector were process in such a way as to obtain minute variations of harmonic components. In order to compare these variations with the Earth magnetic field state, we used minute variations of the field horizontal and vertical components obtained at the magnetic observatory of IKIR FEB RAS. We analyzed the events on March 18-21 and on August 24-28, 2018. The processing results are illustrated in Fig. 2, 3.

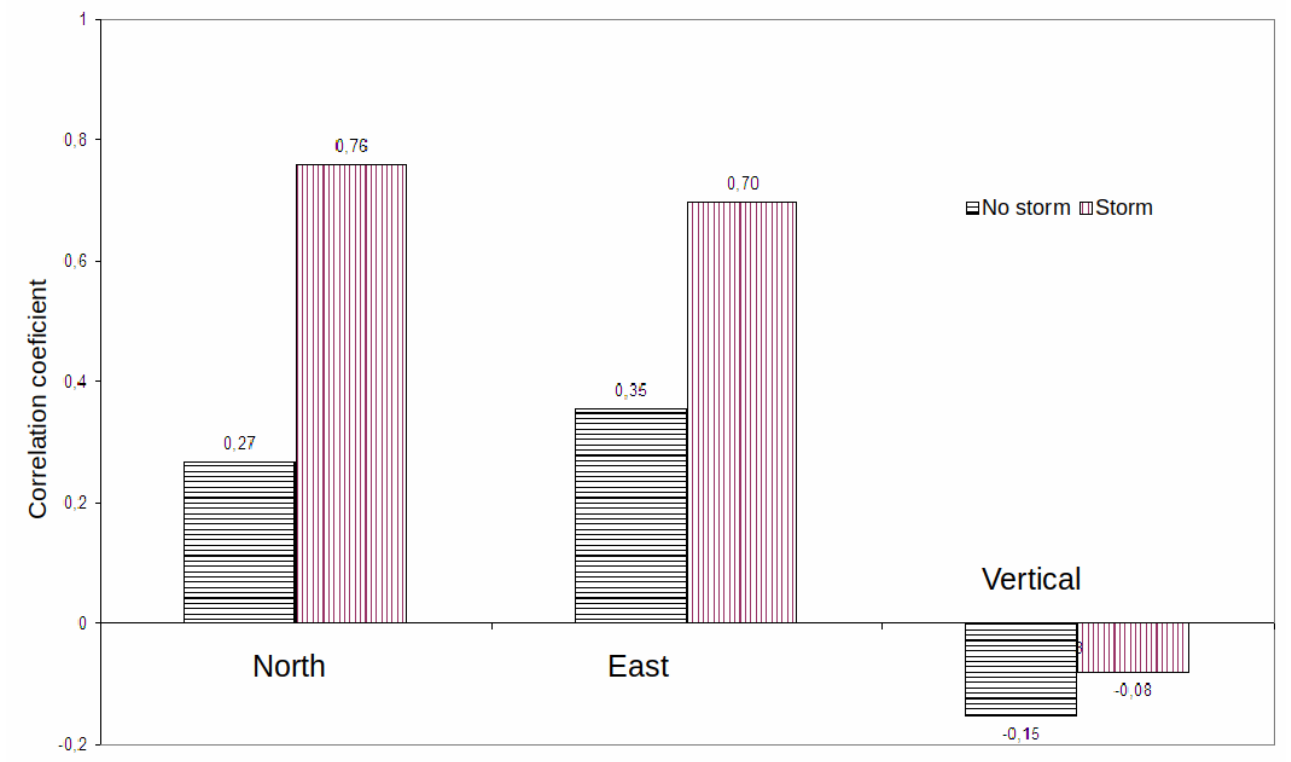

Figure 2. Correlation coefficients of higher harmonics with Earth magnetic field component variations on March 18-21, 2018.

It is clear from the graphs that the current sixth harmonic shows high correlation with the horizontal northern component variations of the Earth magnetic field. 


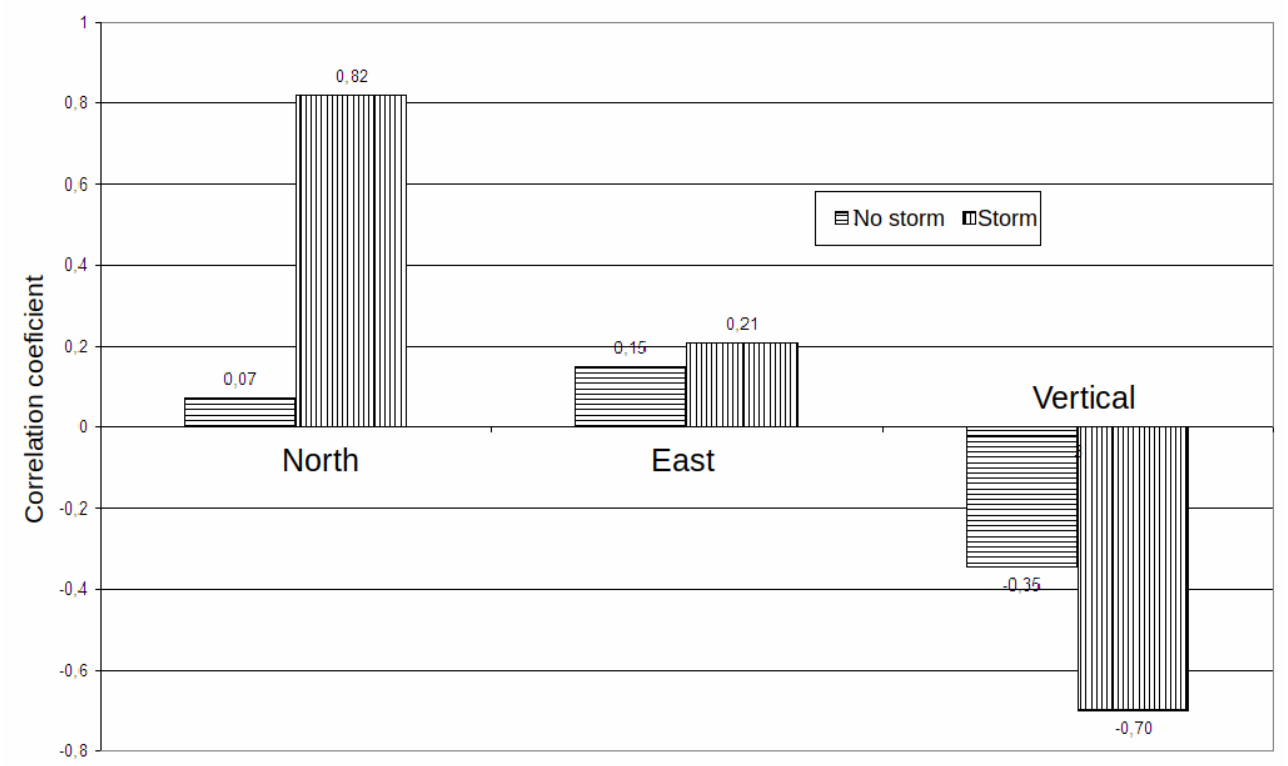

Figure 3. Correlation coefficients of higher harmonics with the Earth magnetic field component variations on August 24-28, 2018.

It was stated in the course of data processing that field variations are not always accompanied by the increase in higher harmonic components, Fig. 4.

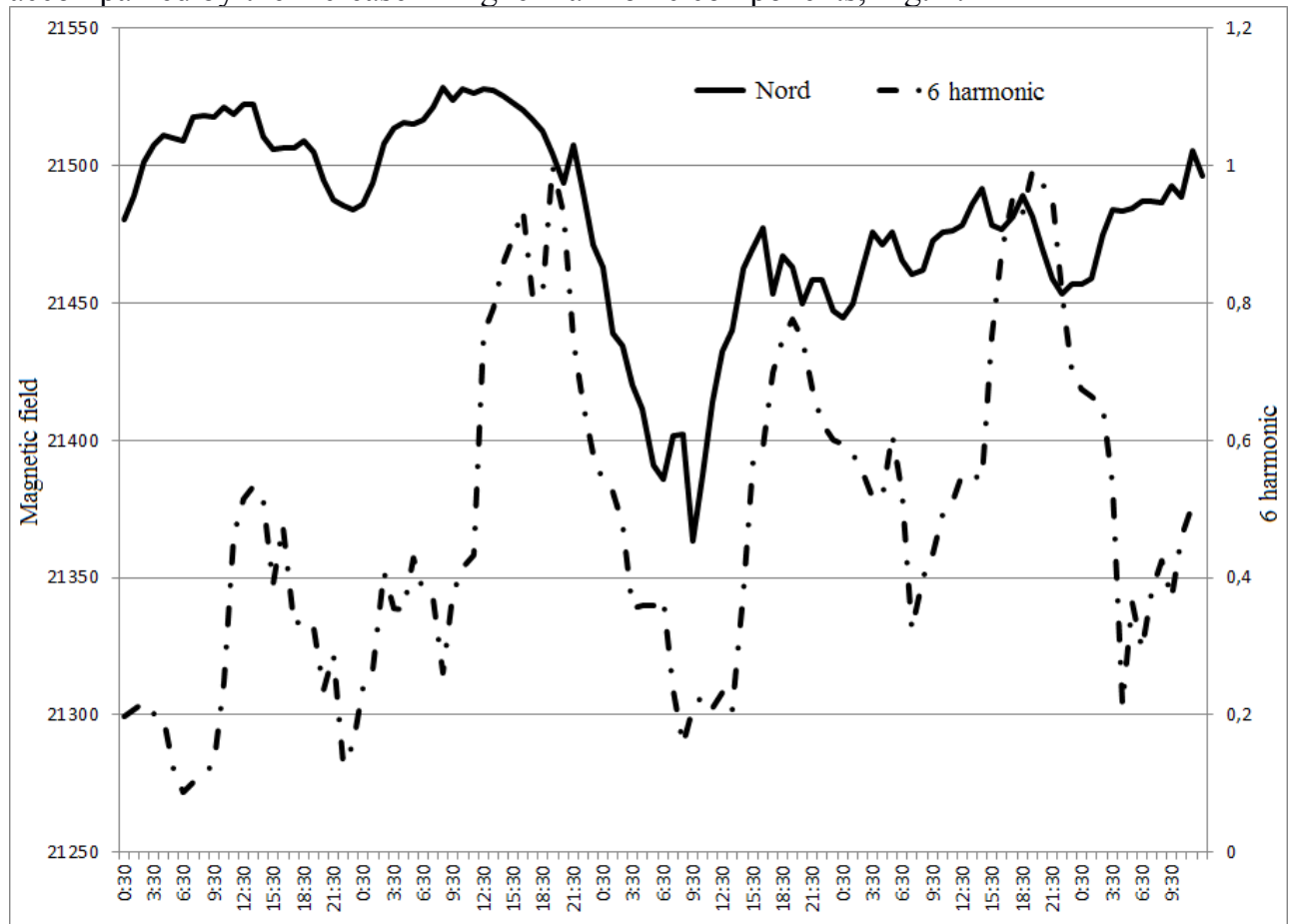

Figure 4. Comparison of field variations and harmonic 6 level changes on August 24-28, 2018. 


\section{Conclusions}

1. The data obtained from a high-tension line showed better efficiency of the method compared to low-tension network.

2. It is reasonable to use intensity harmonics 6 and 8 for GIC diagnostics.

The paper was supported by RFBR Grant No.19-05-00543.

The work was carried out by the means of the Common Use Centre "North-Eastern Heliogeophysical Center" CKP_558279.

\section{References}

1. V.P. Sivokon', A.S. Serovetnikov, A.V. Pisarev, Elektro. Elektrotekhnika, elektroenergetika, elektrotekhnicheskaya promyshlennost', 3, 30-34 (2011) (In Russian)

2. V.P. Sivokon', A.S. Serovetnikov, Elektro. Elektrotekhnika, elektroenergetika, elektrotekhnicheskaya promyshlennost', 3, 19-22 (2013) (In Russian)

3. V.P. Sivokon', A.S. Serovetnikov, Elektro. Elektrotekhnika, elektroenergetika, elektrotekhnicheskaya promyshlennost', 1, 15-18 (2015) (In Russian) 